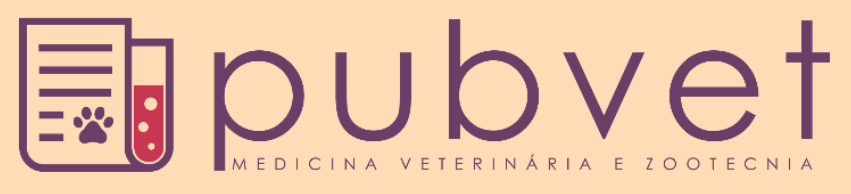

https://doi.org/10.31533/pubvet.v12n9a174.1-7

\title{
Pênfigo foliáceo em um cão jovem sem raça definida: relato de caso
}

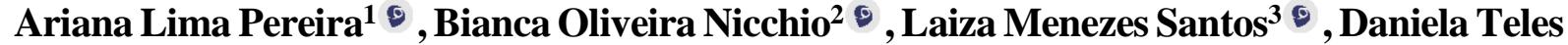 \\ Lima $^{4}$, João Lucas da Silva Bahia Amorim Ferreira ${ }^{5}$, Indiana Gomes da Silva ${ }^{6}$, Rodrigo \\ Lima Carneiro ${ }^{7 *}$
}

${ }^{I}$ Médica Veterinária, Aprimoranda da Clínica Médica de Pequenos Animais, Hospital Veterinário da UNIME, Lauro de Freitas-BA-Brasil. E-mail: arianna.limavet@gmail.com

${ }^{2}$ Médica Veterinária, Mestranda em Ciência Animal nos Trópicos, Professora de Clínica Médica de Pequenos Animais, UNIME, Lauro de Freitas-BA-Brasil. E-mail: bianca.nicchio@gmail.com

${ }^{3}$ Médica Veterinária autônoma, Especialista em Clínica Médica Geral de Pequenos Animais, Lauro de Freitas-BA-Brasil. E-mail: laizamenezes.vet@ gmail.com ${ }^{4}$ Médica Veterinária, Aprimoranda da Clínica Médica de Pequenos Animais, Hospital Veterinário da UNIME, Lauro de Freitas-BA-Brasil. E-mail: danielalteles@gmail.com

${ }^{5}$ Médico Veterinário, Aprimorando da Clínica Médica de Pequenos Animais, Hospital Veterinário da UNIME, Lauro de Freitas-BA-Brasil. E-mail: jamorinvet11@gmail.com

${ }^{6}$ Médica Veterinária, Aprimoranda da Clínica Médica de Pequenos Animais, Hospital Veterinário da UNIME, Lauro de Freitas-BA-Brasil. E-mail: indyana.3@hotmail.com

${ }^{7}$ Médico Veterinário, PhD, Professor de Farmacologia, UNEB-Campus IX, Barreiras-BA-Brasil. E-mail: carneiro.rodrigolima@gmail.com

RESUMO. As dermatopatias autoimunes são aquelas nos quais anticorpos próprios são direcionados contra algum componente da pele. No caso do complexo pênfigo, esses anticorpos são direcionados contra proteínas responsáveis pela adesão celular da epiderme, formando pústulas. O complexo pênfigo está classificado em pênfigo eritematoso, panepidermal, foliáceo, paraneoplásico, vulgar e vegetante, destes o pênfigo foliáceo tem sido mais observado na rotina clínica e a principal alteração observada é a presença de vesículas, pústulas e crostas encontradas bilateralmente nas regiões dorsal, abdominal ventral, axilar e membros. O diagnóstico dessa enfermidade ocorre através de histórico, anamnese, exames complementares como citologia de pele e histopatológico. O tratamento é longo e consiste basicamente em suprimir a resposta imunológica do paciente. Para isso, o principal fármaco utilizado é a Prednisolona. O prognóstico é reservado, devido às complicações inevitáveis do uso prolongado de corticosteróide. O presente artigo teve como objetivo relatar um caso de Pênfigo Foliáceo, em um paciente da espécie canina, macho, com um ano de idade, sem raça definida (SRD) atendido no Hospital Veterinário da UNIME - Lauro de Freitas, BA. A resposta rápida do paciente ao tratamento com uso de corticóide mostrou-se eficaz para a remissão dos sinais clínicos.

Palavras-chave: dermatopatia autoimune, corticoesteroide, cão

\section{Pemphigus foliaceus in a young dog without a defined breed: case report}

ABSTRACT. Autoimmune skin diseases are those in which proper antibodies are directed against some component of the skin. The antibodies of pemphigus complex are directed against proteins responsible for the cellular epidermis adhesion, forming pustules. Pemphigus complex is classified as pemphigus erythematosus, panepidermal, foliaceous, paraneoplastic, vulgar and vegetative, of which pemphigus foliaceus has been more frequently observed in the clinical routine and the main alteration observed is presence of vesicles, pustules and crusts bilaterally found in dorsal, abdominal ventral, axilla and limbs. The diagnosis of this disease is based on historic, anamnesis and complementary exams, such as skin cytology and histopathologic. The treatment is lenghty and basically consists in suppressing patient's immune response. The main drug used is Prednisolone and 
prognosis is reserved, due to the inevitable complications of prolonged use of corticosteroids. The aim of this article was to report a case of Pemphigus Foliaceus in dog, male, undefined breed treated at the Veterinary Hospital of UNIME - Lauro de Freitas, Bahia. The patient's rapid response to treatment with corticosteroids was shown to be effective for the remission of clinical signs.

Keywords: autoimmune dermatopathy, corticosteroid, dog

\section{Pénfigo foliáceo en un perro joven mestizo: relato de caso}

RESUMEN. Las dermopatías autoinmunes son aquellas en las que los anticuerpos propios se dirigen contra algún componente de la piel. En el caso del complejo pénfigo, estos anticuerpos se dirigen contra las proteínas responsables de la adhesión celular de la epidermis, formando pústulas. El complejo pénfigo está clasificado en pénfigo eritematoso, panepidermal, foliáceo, paraneoplásico, vulgar y vegetante, de éstos el pénfigo foliáceo ha sido más observado en la rutina clínica y la principal alteración observada es la presencia de vesículas, pústulas y costras encontradas bilateralmente en las regiones dorsal, abdominal, ventral, axilar y miembros. El diagnóstico de esta enfermedad ocurre a través de histórico, anamnesis, exámenes complementarios como citología de piel e histopatológico. El tratamiento es largo y consiste básicamente en suprimir la respuesta inmune del paciente. Para ello, el principal fármaco utilizado es la Prednisolona. El pronóstico es reservado, debido a las complicaciones inevitables del uso prolongado de corticosteroides. El presente artículo tuvo como objetivo relatar un caso de Pénfigo Foliáceo, en un paciente de la especie canina, macho, mestizo con un año de edad, atendido en el Hospital Veterinario de la UNIME - Lauro de Freitas, BA. La respuesta rápida del paciente al tratamiento con el uso de corticoides se mostró eficaz para la remisión de los signos clínicos.

Palabras clave: dermopatía autoinmune, corticoesteroide, perro

\section{Introdução}

O pênfigo foliáceo $(\mathrm{PF})$ é uma dermatopatia autoimune caracterizada pela deposição de anticorpos nos componentes de adesão (proteínas) que formam a epiderme, causando a sua destruição (acantólise) e formação de pústulas (Balda et al., 2008). O complexo pênfigo é classificado de acordo com o local de ação dos auto-anticorpos na epiderme que no caso do pênfigo foliáceo a proteína alvo é a desmogleína I da superfície dos queratinócitos (Scarff, 2009). Assim, o complexo pênfigo (Petermann, 2015) é classificado em: pênfigo vulgar (PV), pênfigo foliáceo (PF), pênfigo vegetante $(\mathrm{PVg})$, pênfigo eritematoso (PE), pênfigo panepidermal (PP) e pênfigo paraneoplásico (PPP).

O PF é a dermatopatia mais comum dentre as doenças que abarcam o complexo pênfigo (Larsson, 2009). Ele acomete cães e gatos com maior frequência, com faixa etária entre 4-9 anos, fêmeas e animais de raça definida (Balda et al., 2008). Os sinais clínicos observados são pústulas que evoluem para crostas, além de febre, dor, claudicação, edema, depressão, linfoadenopatia e prurido (Olivry \& Linder, 2009).
O diagnóstico desta doença ocorre através do histórico, anamnese, exames complementares como citologia de pele e histopatologia (Barbosa et al., 2012; Patel \& Forsythe, 2010). O do PF é longo e consiste em suprimir a resposta imunológica do paciente, sendo a prednisolona o fármaco de eleição, entretanto outros princípios ativos podem ser utilizados tais como: azatioprina, clorambucil, ciclosporina, tacrolimus, e crisoterapia, micofenato de mofetil, ciclofosfamida, tetraciclina e nicotinamida (Sandra, 2003; Tóth \& Jonkman, 2001).

Objetivou-se com este trabalho relatar um caso de pênfigo foliáceo em um cão, com 1 ano e 6 meses de idade, macho, sem raça definida atendido pela clínica médica de pequenos animais no Hospital Veterinário (HOSVET) - UNIME em Lauro de Freiras, Bahia.

\section{Relato de caso}

Um cão, sem raça definida, de 1 ano e 6 meses de idade, com histórico clínico de alopecia, pústulas, crostas na região abdominal, pélvica, membros, cabeça, cauda e prurido moderado há cerca de 2 meses, foi atendido no Hospital 
Veterinário da UNIME, no município de Lauro de Freitas, BA. Ao exame físico dermatológico, o animal apresentava as seguintes lesões: crostas, pústulas e alopecia em região da cabeça, plano nasal e cauda (Figura 1-A), ambas as faces internas das orelhas apresentavam pústulas (Figura 1-B) e secreção amarronzada em ambos os condutos auditivos, na região cervical apresentava área de alopecia com lesão úmida com bordas hiperêmicas (Figura 1-C). Na região do dorso pode-se observar alopecia e descamação da pele (Figura 1-D) e na região ventral dos membros pélvicos observou-se pústula, crostas, edema e eritema do prepúcio (Figura 1-E). Os parâmetros vitais avaliados estavam dentro da normalidade para espécie, com exceção dos linfonodos (submandibulares, pré-escapulares e poplíteos) que se apresentavam aumentados. $\mathrm{O}$ paciente apresentava claudicação em membro pélvico direito, devido luxação da patela de grau 2.

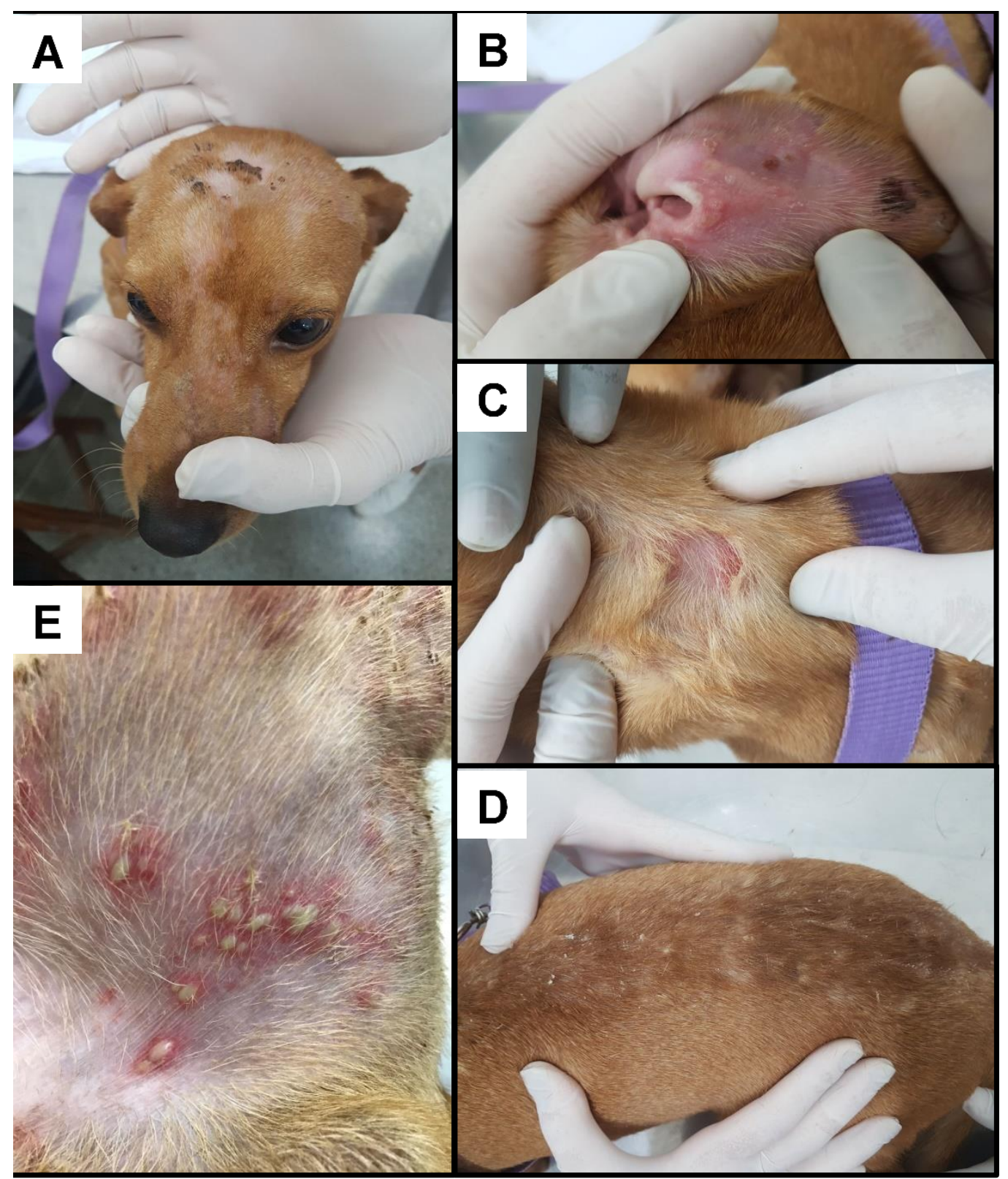

Figura 1. Principais lesões observadas no primeiro atendimento. A. Alopecia, crostas e eritema em cabeça e focinho. B. Pústulas em face interna de pavilhão auricular. C. Alopecia e eritema em região cervical. D. Alopecia e descamação em região dorsal. E. Face interna da coxa com eritema, pústulas e colaretes. Fonte: Clínica Médica de Pequenos Animais - HOSVET.

Os seguintes exames complementares foram solicitados: Hemograma, Ureia, Creatinina, Citologia de pele e ouvido, Parasitológico de Pele, Cultura Fúngica, Alanino Amino Transferase
(ALT) e Fosfatase Alcalina (FA) e Sorologia Leishmaniose. No mesmo dia do atendimento, foi prescrito Tramadol $(2 \mathrm{mg} / \mathrm{kg})$ por via oral (VO) a cada 8 horas durante 5 dias. $O$ resultado da triagem 
dermatológica indicou as seguintes alterações: citologia de pele e ouvido, presença de cocos (raros) e raras Malassezia também; o parasitológico de pele foi negativo para ácaros; a cultura fúngica demonstrou crescimento de um fungo ambiental Mucor spp; a sorologia para Leishmaniose não foi reagente ao teste ensaio imunoenzimático (ELISA).

Após os resultados, a terapêutica inicial utilizada para dermatopatia foi a seguinte: banhos a cada 72 horas com shampoo (Cloredixina a $2 \%$ e Miconazol a 2,5\%) durante 30 dias, antibiótico tópico Mupirocina pomada diluída em água fervida e filtrada, borrifar a solução a cada 12 horas durante 21 dias diretamente nas lesões. Para o tratamento otológico foi prescrito uma solução de limpeza (ácido salicílico e ácido lático) a cada 24 horas, durante 5 dias e a utilização de medicamento otológico (gentamicina, betametasona e cetoconazol), a cada 12 horas durante 15 dias.

Quatro dias após iniciado o tratamento o tutor retornou ao HOSVET para informar que não havia melhora do quadro do paciente, então foram prescritos, antibiótico Amoxicilina Clavulanato de Potássio $(20 \mathrm{mg} / \mathrm{Kg})$ por via oral a cada 12 horas durante 28 dias, suplemento vitamínico (ácido fólico, arginina, biotina, lisina, metionina, mananoliogossacarídeo,

Saccharomycescerevisiae, treonina, triptofano, vitamina B12, B6 e E) 2 gramas a cada 24 horas durante 30 dias e suspenso o antibiótico tópico. No entanto, dezoito dias após o tratamento inicial houve piora do quadro clínico, o prurido se tornou intenso, as lesões localizadas passaram a ser generalizadas (pústulas em toda região ventral).

Mediante o quadro clínico apresentado foram solicitados os seguintes exames complementares: nova citologia da pele através de imprint de uma pústula rompida, e biópsia da pele das pústulas íntegras da face ventral do pavilhão auricular, e da região ventral do membro pélvico direito respectivamente (Figura 2-A). Após anestesia para a realização da biópsia, foi realizada técnica incisão em forma de elipse, divulsão e corte da pele com pústulas íntegras e recentes. Em seguida, o material foi encaminhado para análise histopatológica em formol a 10\%, os fragmentos de pele foram processados rotineiramente, e coradas pela hematoxilina e eosina. Sendo assim, foi prescrito Prednisolona $(2 \mathrm{mg} / \mathrm{kg})$ a cada 24 horas por via oral até novas recomendações, como também continuar os banhos terapêuticos como descritos anteriormente, e realizar a limpeza da ferida da biópsia com solução fisiológica e digliconato de clorexidine a cada 24 horas até a cicatrização.

O proprietário retornou sete dias após a realização da biópsia e relatou melhora significativa do quadro clínico do paciente, com ausência de pústulas e crostas nos locais anteriormente citados (Figura 2-B).

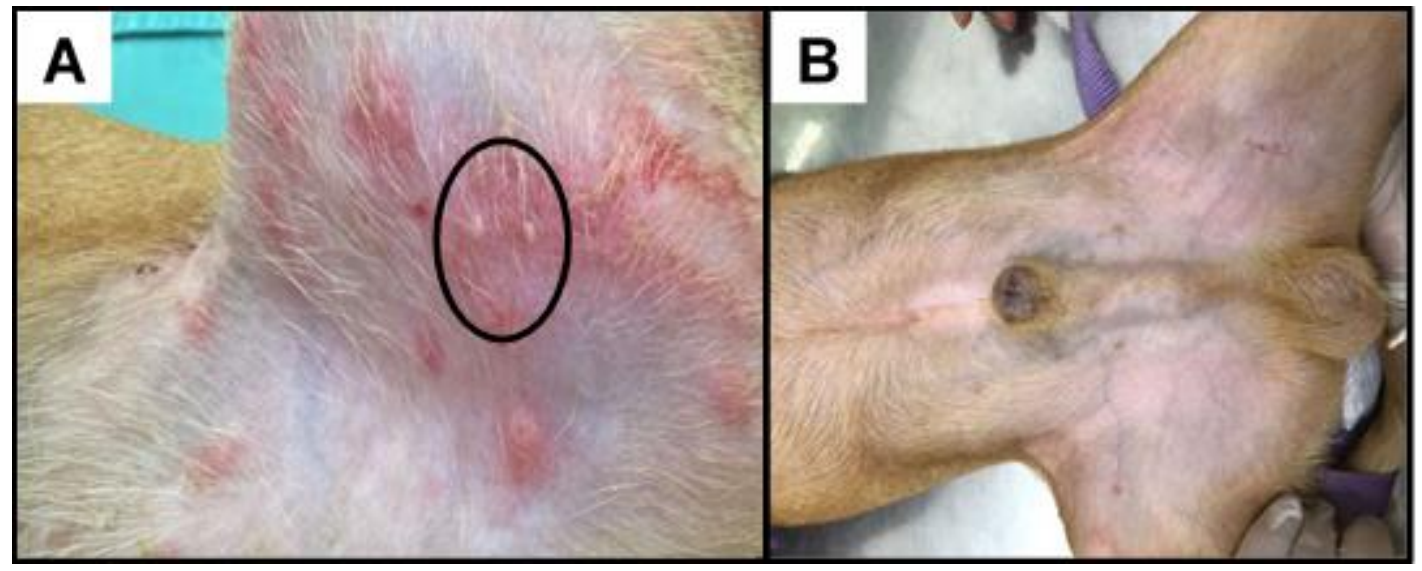

Figura 2. A. Localização das pústulas íntegras para realização da biópsia; B. Paciente após 7 dias de tratamento, sem pústulas no local da biópsia. Fonte: Clínica Médica de Pequenos Animais HOSVET.

O resultado da citologia da pele demonstrou moderada quantidade de queratinócitos nucleados de forma redonda, com núcleo grande, nucléolo proeminente e intensa coloração citoplasmática, sugestivo de acantócitos (Figura 3-B). O resultado histopatológico da pele demonstrou a presença de pústulas epidérmicas subcorneais (Figura 3-A) intraespinhosa, contendo no seu interior poucas células acantolíticas acompanhadas pela presença discreta de infiltrado inflamatório polimorfonuclear, em região de derme superior, foi observado à presença de moderado infiltrado inflamatório predominantemente polimorfonuclear (Figura 3-C). 

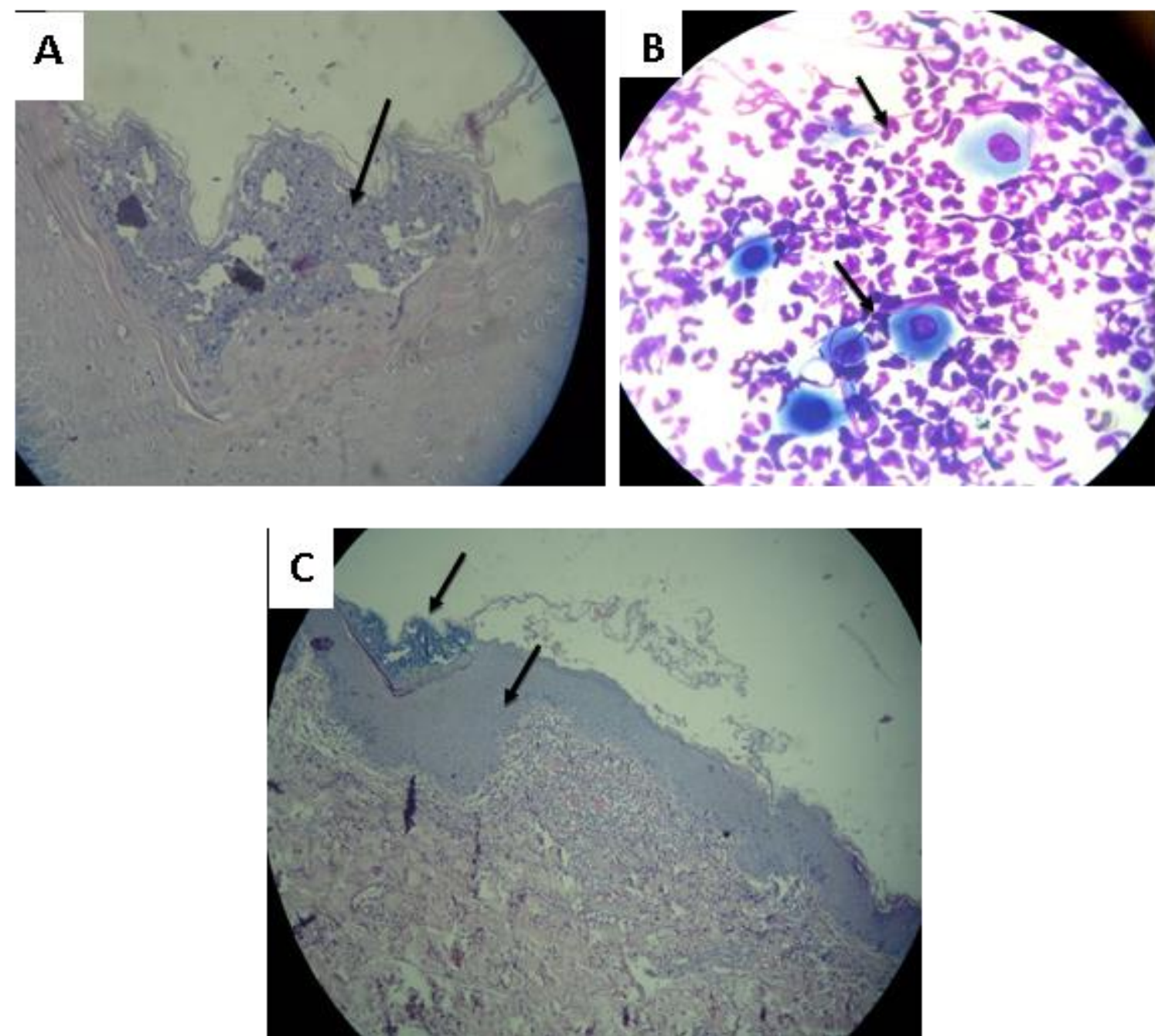

Figure 3. A. Pústula epidérmica com infiltrado inflamatório e células acantolíticas (seta); B. Neutrófilo e queratinócitos acantolíticos (setas) na preparação citológica; C. Pústula epidérmica e região de derme superior com infiltrado inflamatório. Corante Hematoxilina e Eosina. Aumento em 40x e 1000x. Fonte: Laboratório de Patologia Animal e Patologia Clínica HOSVET.

Após o diagnóstico da enfermidade foi solicitado ao proprietário retornar periodicamente ao HOSVET para reavaliação da pele e iniciar o desmame do corticóide, porém após a última consulta um mês após inicio do tratamento o paciente não retornou ao hospital. No último atendimento foi possível verificar que as lesões pustulares e crostosas anteriormente citadas haviam desaparecido, como observado na face interna da orelha (Figura 4-A), mas haviam algumas áreas com alopecia na cabeça (Figura 4B), ponta da cauda (Figura 4-C) e pápula na face interna do membro pélvico (Figura 4-D).

\section{Discussão}

O pênfigo foliáceo é uma dermatopatia autoimune no qual anticorpos são dirigidos contra componentes da epiderme em especial as proteínas de adesão nos desmossomos, resultando em acantólise e formação de vesículas (Larsson, 2009). Em estudo restrospectivo de agosto de 2000 a julho de 2005 , em 43 casos o pênfigo acometeu cerca de 76,7\% (33/43 casos) animais com raça definida, tais como Cocker spaniel, Daschund e Akita, com faixa etária entre 4-9 anos e 55,8\% (24/43 casos) são fêmeas (Balda et al., 2008).O presente trabalho relatou um caso de pênfigo foliáceo em um cão sem raça definida, com 1 ano e 6 meses de idade, e com apresentação clínica de prurido moderado, lesões alopécicas, pústulas e crostas na região abdominal, pélvica, patas, cabeça, cauda há cerca de 2 meses. Portanto, o achado encontrado no relato é contrário aos encontrados pelos autores anteriormente citados.

Os sinais clínicos marcantes no PF são crostas, raras pústulas que rapidamente se rompem e dão lugar a colateres epidérmico (Moraillon et al., 2007), tais achados são semelhantes aos descritos 
no caso. A etiologia desta enfermidade é considerada complexa, pois vários fatores podem desencadear essa dermatopatia, seja ela devido a reações medicamentosas, exposição a luz solar, decorrente de problemas crônicos de pele e de forma espontânea (Scarff, 2009). No caso relatado acredita-se o pênfigo foliáceo ocorreu de forma espontânea, visto que nenhum outro processo dentro da etiologia desencadeou o inicio da enfermidade.

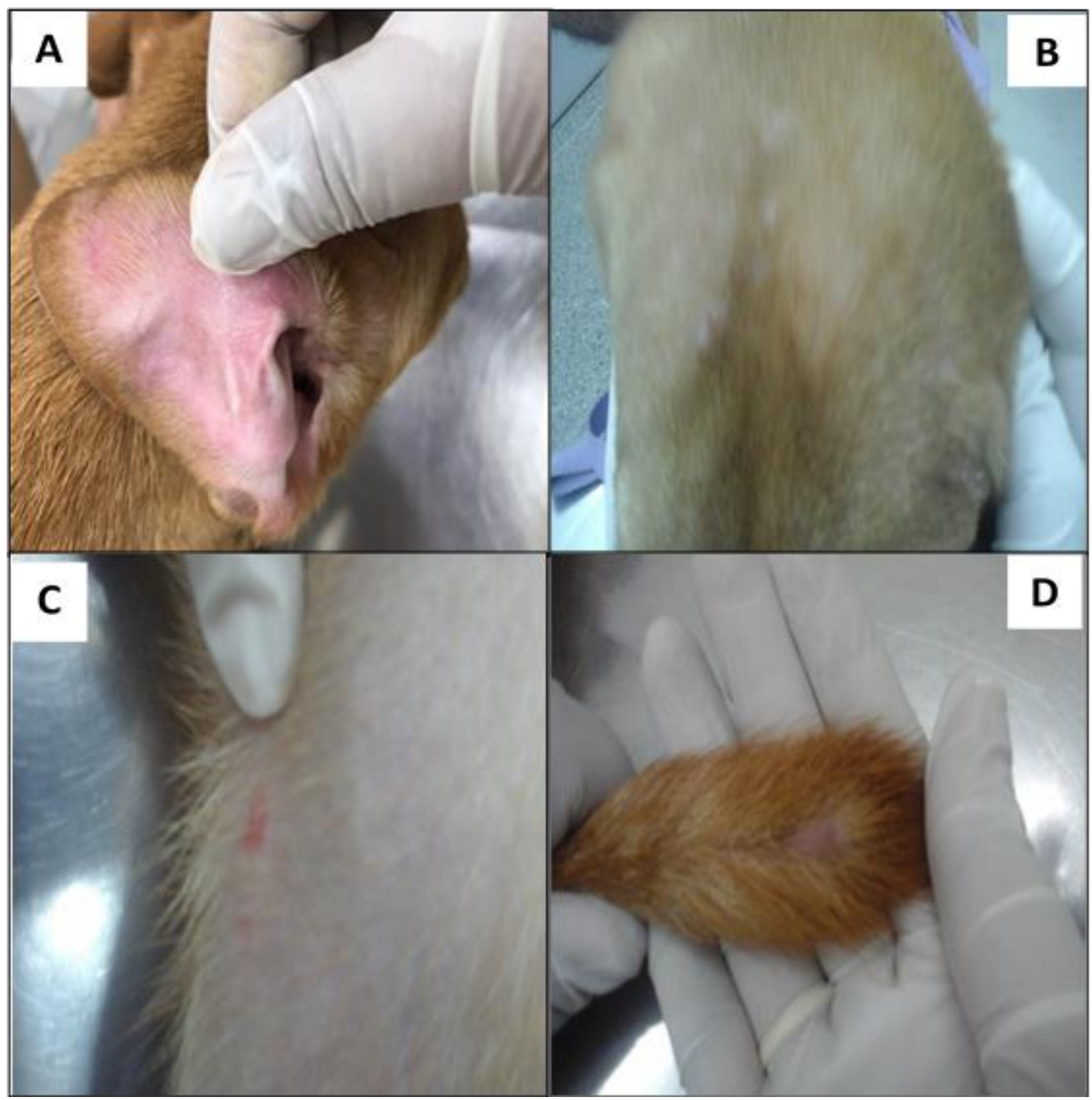

Figura 4. A. Face interna da orelha com ausência de pústulas e crostas; B. Cabeça com áreas de alopecia; C. Face interna do membro pélvico com pápulas; D. Ponta da cauda com área de alopecia. Fonte: Clínica Médica de Pequenos Animais HOSVET.

A localização das lesões mais observadas são cabeça, orelhas, membros e região inguinal, a medida que as pústulas se rompem dão lugar a colaretes epidérmicos e crostas nessas regiões (Larsson, 2005), esses locais são coerentes com os encontrados no caso, com exceção da cauda que não foi descrito em nenhuma literatura citada no presente relato.

O diagnóstico do pênfigo foliáceo está arraigado na anamnese, sinais clínicos e a realização de exames dermatológicos, tais como parasitológico de pele, citologia de pele, cultura fúngica e finalmente histopatologia da pele, podese utilizar testes imunológicos, mas devido o seu custo a sua utilização ainda não é uma realidade na Medicina Veterinária (Paulo, 2016).

Os resultados observados na citologia foram a presença de uma quantidade moderada de queratinócitos nucleados de forma redonda, com núcleo proeminente e intensa coloração citoplasmática sugestivo de acantócitos. $\mathrm{Na}$ citologia de pústulas íntegras são observados 
células acantolíticas soltas na epiderme, desprovidas de adesão, esféricas e com hipercromasia dos núcleos, sendo demoninados de células de Tzank (Balda et al., 2008), compatíveis com os achados encontrados no relato.

$\mathrm{Na}$ microscopia do fragmento da pele foi observado a presença de pústulas epidérmicas subcorneais, intraespinhosa, contendo em seu interior poucas células acantolíticas, com a presença de infiltrado inflamatório polimorfonuclear na epiderme e derme. Histologicamente serão observados inicialmente vesículas preenchidas por queratinócitos acantolíticos e raros neutrófilos, que evoluem para pústulas subcorneais, com queratinócitos acantolíticos dispersos (Lucarts, 2010), assim como foi observado no presente relato.

O tratamento instituido no relato foi a administração de Prednisolona $(2 \mathrm{mg} / \mathrm{kg})$ por via oral a cada 24 horas até a remissão dos sinais clínicos, no período de uma semana foi possivel observar uma melhora significativa do paciente. $\mathrm{O}$ uso da prednisolona na dose 1-2 $\mathrm{mg} / \mathrm{kg} /$ diariamente ainda é o fármaco de eleição, e a sua dose deve ser reduzida conforme melhora das lesões (Lucarts, 2010), assim como foi observado no caso relatado.

A utilização de corticóides tem se mostrado eficaz no tratamento do PF, a única desvantagem são as complicações pelo uso prolongado como poliuria, polidipsia, infecções recorrentes do trato urinário inferior entre outros (Patel \& Forsythe, 2010). No caso relatado durante o período que o paciente esteve acompanhado, não foi verificado pelo tutor nenhuma dessas complicações citadas anteriormente, mas o mesmo foi alertado sobre tal fato.

\section{Conclusão}

O pênfigo foliáceo quando diagnosticado precocemente pode ter boa resposta ao tratamento, como ocorreu no caso relatado. $\mathrm{O}$ exame histopatológico se mostrou determinante para a conclusão do caso, e o uso do corticóide se mostrou eficaz para o tratamento inicial do paciente.

\section{Referências bibliográficas}

Balda, A. C., Ikeda, M. O., Larsson Junior, C. E., Michalany, N. S. \& Larsson C. E. 2008. Pênfigo foliáceo canino: estudo retrospectivo de 43 casos e terapia (2000-2005). Pesquisa Veterinária Brasileira, 28(28), 387-392.

Barbosa, M. F., Fukahori, F. L. P., Dias, M. B. M. C. \& Lima, E. R. 2012. Patofisiologia do Pênfigo Foliáceo em cães: revisão de literatura. Medicina Veterinária (UFRPE), 6(3), 26-31 .

Larsson, C. E. Pemphigus Complex (Wildfire): Epidemiologia e Clínicas. Proceedings of the 34th Workd Small Animal Veterinary Congress WSAVA. São Paulo, Brasil: [s.n.]. 2009.

Lucarts, L. E. B. Avaliação de exequibilidade e da efetividade da determinação de anticorpos séricos pela IFI, em cães acometidos por pênfigo foliáceo pré e trans-terapia. Repositório Institucuinal UNESP, São Paulo, 2010.

Moraillon, R., Boussarie, Y. L. D. \& Sénécat, O. 2007. Manual elsevier de veterinária: Diagnóstico e tratamento de cães, gatos e animais exóticos (7a ed.). Elsevier, Rio de Janeiro, BR.

Olivry, T. \& Linder, K. E. 2009. Dermatoses affecting desmosomes in animals: a mechanistisc review of acantholytic blistering skin diseases. Veterinary Dermatology, 20, 313-326.

Patel, A. \& Forsythe, P. 2010. Dermatologia em Pequenos Animais. Elsevier, Rio de Janeiro, BR.

Paulo, M. R. et al. Pênfigo foliáceo supostamente induzido por cefalexina em cães- Relato de caso. Biblioteca Virtual em Medicina Veterinária e Zootecnia, São Paulo, 2016.

Petermann, M. Pemphigus foliaceus in dogs: the imunne pathogenesis and terapies. Why are some dogs not responsive to the tratament? https: //lib.ugent.be, 2015.

Sandra, M. Pemphigus. 2003. In: Foster, A. P., Foil, C. S. BSAVA Manual of Small Animal Dermatology (2a. ed., p. 189-196). Bristish Small Animal Veterinary Association, Gloucester, Reino Unido.

Scarff, D. 2009. Pemphigus in the dog and cat. Part 1: Aetiology, pathogenesis and clinical signs. Companion Animal, 14(9), 1-4.

Tóth, G. G. \& Jonkman, M. F. 2001. Therapy of Pemphigus. Clinics in Dermatology, 19, 761-767.

Recebido: 2 Julho, 2018.

Aprovado: 26 Julho, 2018

Publicado: 3 Setembro, 2018

Licenciamento: Este artigo é publicado na modalidade Acesso Aberto sob a licença Creative Commons Atribuição 4.0 (CC-BY 4.0), a qual permite uso irrestrito, distribuição, reprodução em qualquer meio, desde que o autor e a fonte sejam devidamente creditados. 